\title{
From Oil to Stock Markets
}

\author{
Khaled Guesmi \\ IPAG Lab, IPAG Business School, Paris, France \\ Heni Boubaker \\ IPAG Lab, IPAG Business School, Paris, France \\ Van Son Lai \\ Laval University, Faculty of Business Administration, Quebec, Canada
}

\begin{abstract}
This study investigates the impacts of crude oil price variations on the French and American stock market returns using daily observations of Brent crude oil prices, the CAC40, and the Dow Jones Industrial Average indexes for the period of 1999 2012. Our results show strong evidence of fractional cointegration between oil and stock market indices, suggesting the presence of a relationship that governs their long-run joint movements. We find that dynamic correlations increase dramatically during crisis periods, but they move towards their initial levels after those periods. The effect of the lower oil price on the development of the global economy depends not only on whether the low price is expected to be temporary or persistent but also on the causes of the oil price fall. Market analysis shows that the new price levels of oil are caused by the simple mechanism of supply and demand. The low price of oil in 2014 is caused by reduced oil demand because of the slower economic growth in Chinese economy and the impact of developed world's drive to reduce carbon emissions on the oil market. Given
\end{abstract}

\footnotetext{
* Corresponding Author: Khaled Guesmi; Department of Finance (IPAG Lab), IPAG Business School, 184 Boulevard St Germain 75006 Paris, France; Tel: +33 01550440, Fax: +33 0145444046, E-mail: khaled.guesmi@ipag.fr.

Co-author: Heni Boubaker; Department of Finance (IPAG Lab), IPAG Business School, 184 Boulevard St Germain 75006 Paris, France; Tel: +33 01550489, Fax: +33 0145444046, E-mail: heniboubaker@gmail.com.

Van Son Lai; Department of Finance and Insurance, FSA ULaval, Pavillon Palasis-Prince, Local 3626, Quebec, Canada; Tel: +418 656131, Fax: +418 6562624, E-mail: VanSon.Lai@fsa.ulaval.ca.
} 
the country-specific dynamic links between oil and stock markets, policymakers may make appropriate policies to reduce the impact of adverse oil price effects on production and economic activities, while investors can optimally design their diversification and hedging strategies, considering oil price persistence patterns.

JEL Classifications: C10, E44, G15

Keywords: Oil Prices, Stock Markets, Multivariate Fractional Cointegration, Corrected Dynamic Conditional Correlation Fractionally Integrated Asymmetric Power Autoregressive Conditional Heteroskedasticity (c-DCC-FIAPARCH)

\section{Introduction}

There is now a considerable research on the relationship between oil prices and stock markets. To the extent that crude oil serves as an important input for industrial and economic activity, the price of oil may affect the aggregate stock prices through influencing negatively the real output which, in turn, lowers corporate earnings and thus the sum of discounted future cash flows (Hamilton 1983, Cunado and Perez de Garcia 2005, Cologni and Manera 2008). By contrast, fluctuations in stock markets may help to predict oil price movements because they reflect closely market conditions in which firms are operating (Arouri et al. 2012).

Gao and Suss (2015) show that financial investors represent $80 \%$ of the total investors in a commodity market, the most important commodity being crude oil, leading to grant more attention to its prices than those of other commodities. More specifically the attention to crude oil price has grown since the end of the 1990s when different financial crises and events have occurred leading to boom or bust in international trade and as a consequence, proving the characteristic of the high volatility of oil prices. Therefore, the interaction between crude oil and financial markets has been the subject of serious consideration from both finance practitioners and academicians.

Furthermore, the stock price is given by discounting all expected future cash flows at the investors' required rate of return. A negative oil shock may reduce the corporate cash flow and the rate of return depending on economic conditions. If the low oil price is expected to be long lasting, the economy will be affected more strongly than if the 
price decrease is expected to be provisional, as companies and consumers react more strongly to a permanently lower oil price. ${ }^{1}$ However, the effect of the lower oil price on the development of the global economy depends not only on whether the low price is expected to be temporary or persistent but also on the causes of the oil price fall. Hervé et al. (2008), Peersman and Van Robays (2012), and Cashin et al. (2014) show that a price fall due to reduced oil demand haven't had the same positive effects on the global economy as a price fall due to an increased oil supply. This is caused by a demand-driven price which is symptomatic of worsened growth prospects. The extent of the effects also depends on how countries adjust their fiscal and monetary policies in response to the fall in prices.

From Kilan (2009) and Creti et al. (2014) we consider origins of oil price shocks: aggregate demand-side shock, precautionary demand shock, and supply-side shock. Despite the fact that oil price effects on macroeconomic variables have been extensively studied, the literature on the relationship between stock market and oil prices is still growing.

\section{Literature Review}

There are already a few attempts on the aforementioned topic, but none of the existing papers offers a multivariate analysis, which is the multivariate fractionally integrated processes that use the parametric bootstrap to test the existence of cointegration and the measure of the dynamic conditional correlations.

The above-mentioned theoretical predictions have been more or less confirmed by various studies and the oil price effects vary across markets and economic sectors depending on the degree and the nature of oil dependence (Jones and Kaul 1996, Huang and et al. 1996, Sadorsky 1999, Chiou and Lee 2009, Arouri and Nguyen 2010, Filis et al. 2011). For instance, Jones and Kaul (1996) examine the short-term response of four developed equity markets to shocks in oil prices and show that the price of oil plays an important role in explaining the formation of stock returns in the United States and Canada, but not in Japan and the United Kingdom (UK). Using a Vector Autoregression

\footnotetext{
${ }^{1}$ Monetary Policy Report, February 2015.
} 
(VAR) model, Huang et al. (1996) reveals a significant relationship between oil prices and the stock returns of some American oil companies, but insignificant relationship between oil prices and United States (US) market indices such as the S\&P's 500 index. Sadorsky (1999) shows that the US markets react significantly to the fluctuations in oil prices from a VAR model with Generalized Autoregressive Conditional Heteroskedasticity (GARCH) effects. Chiou and Lee (2009) use an Autoregressive Conditional Jump Intensity model to study the effects of expected, unexpected, and negative unexpected oil price fluctuations on the S\&P's 500 index returns. They find that high fluctuations in oil prices have asymmetric unexpected effects on stock returns. From a sector perspective, Arouri and Nguyen (2010), among others, show that the reaction of sector returns in European countries to changes in the price of oil is considerably different across sectors. Moreover, the inclusion of the oil assets into a portfolio of sector stocks leads to the improvement of portfolio's risk-return characteristics. Filis et al. (2011) use a multivariate Dynamic Conditional CorrelationGeneralized Autoregressive Conditional Heteroskedasticity (DCC-GARCH) model to analyze the time-varying correlations between Brent oil prices and stock markets for oil-importing and oil-exporting countries and find that the conditional variances of oil and stock prices do not differ for these two sets of countries. However, the time-varying correlations depend on the nature of the oil shocks because the response to aggregate demand-side shocks is much greater than that to supply-side shocks following the OPEC's production cuts.

Several other studies have looked at the issue of return and volatility transmission between oil and stock returns at both market and sector levels (Malik and Ewing 2009, Arouri et al. 2011). For example, Malik and Ewing (2009) rely on bivariate GARCH models to estimate the volatility transmission between weekly WTI oil prices and equity sector returns, finding evidence of spillover mechanisms. Arouri et al. (2011) employ a generalized VAR-GARCH model to examine the extent of volatility transmission between oil and stock markets in Europe and the United States at the sector level. Their model allows for simultaneous shock transmission in the conditional returns and volatilities. Their findings indicate significant volatility spillover between oil and sector stock returns, but the spillover mechanism is different for stock markets in Europe and the United States. More importantly, Arouri et al. (2011) show that taking the cross-market volatility spillovers estimated from the VAR-GARCH models often leads to higher diversification benefits and hedging effectiveness, as compared to other commonly used multivariate volatility models such as the CCC-GARCH, the diagonal 
BEKK-GARCH, and the DCC-GARCH. In a related study, Choi and Hammoudeh (2010) extend the time-varying correlations analysis by considering the commodity prices of Brent oil, WTI oil, copper, gold and silver, and the S\&P's 500 index. They show that commodity correlations have increased since 2003, which thus limits hedging substitutability in portfolios. ${ }^{2}$

In this article, we extend the related literature by using an integrated approach that allows us to simultaneously examine the short- and long-run links between oil and stock markets. This approach nests the multivariate fractional cointegration approach (Davidson, 2002) and the Corrected Dynamic Conditional Correlation Fractionally Integrated Asymmetric Power ARCH(c-DCC-FIAPARCH) model to analyse the mean and volatility spillover effect between oil price and stock markets.

This multivariate framework is more suitable than the univariate and bivariate ones for considering the interactions between oil price fluctuations and stock markets. A number of multivariate ARCH models have been now developed to capture the conditional heteroscedasticity of financial series. After the Constant Conditional Correlation (CCC) process, Engle (2002) developed the DCC model, describing the time-varying correlations. The major innovation in DCC is in using a two-step estimation to facilitate the computation complexity involved in the parameter estimation of a multivariate process. Further, in DCC-GARCH, any type of GARCH family models with stationary covariance and normally distributed errors can be used to model the volatility of the return rate of a certain single asset. Thus, DCC is more flexible in modelling the volatility of asset return rates and is favorable for getting the most accurate model to describe the volatilities. Accordingly, we decided to adopt the multivariate DCC-GARCH model to gauge the time-variations of the variance-covariance matrix and the conditional correlations. This class of models is distinguished by its simplicity and efficacy when estimating a large conditional covariance matrix because each return series is allowed to follow a univariate GARCH specification.

The Fractionally Integrated Asymmetric Power APARCH (FIAPARCH) model is an extended version of the Asymmetric Power ARCH (APARCH) model of Ding et al. (1993) incorporating a fractionally integrated process as defined by Baillie et al. (1996). By construction, it offers the flexibility to specify the conditional variance process in which volatility reacts asymmetrically to positive and negative shocks. Long-range volatility dependence is easily captured, and the appropriate power of returns can be

\footnotetext{
${ }^{2}$ There is also a large literature that examines the oil-exchange rate nexus. Interested readers can refer to, among others, Cifarelli and Paladino (2010) and Aloui et al. (2013) for a literature survey.
} 
determined to set up the best predictable structure of conditional volatility. We illustrate the usefulness of this empirical framework by considering the dynamic interactions between the Brent oil market and two major stock markets of France and US over the period 1999 2012 which is characterized by a continuously increasing trend of crude oil prices, as well as their long-swings behavior.

More specifically, our study allows us to simultaneously investigate three main issues: i) the long-run causal links between oil and stock markets; ii) the transmission of return and volatility shocks across these markets; iii) the comovement or joint dynamics of oil and stock markets over time with respect to different economic phases which are bullish and bearish phases. The obtained results should be of particular interest to policymakers as unfavorable oil price fluctuations may have severe impacts on stock market performance through reducing corporate cash flows. Also, investors and fund managers can use our results to build appropriate diversification and hedging strategies. If, for example, crude oil and stock markets exhibit long-run volatility dependence, profitable investment strategies can be constructed based on price persistence patterns. Also these markets may not be included in diversification strategies if they establish a long-run equilibrium in the future.

Using daily data for Brent oil prices and the major stock market indices of two oilimporting countries, France and US over the period 1999 2012, we show that the combination of the multivariate fractional cointegration and the c-DCC-FIAPARCH model is useful in gauging the stylized facts of oil-stock market relationships. Indeed, the price series under consideration are fractionally cointegrated within the multivariate framework. Moreover, the comovement between the two markets is typically timevarying and exhibits both asymmetric volatility effects and long-memory patterns.

The rest of the article is organized as follows. Section III introduces the empirical method to assess the links between oil and stock markets in the short- and long-run. Section IV describes the data. Section V discusses the empirical results. Section VI provides some concluding remarks. 


\section{Methodology}

We assess the relationships between crude oil and stock markets by using a multivariate approach. The econometric specification used in our study has two components. To model the series, we combine the multivariate fractional cointegration analysis and the DCC-GARCH-type model to study these relationships. The empirical procedure first requires the identification of the fractionally cointegrating relationships in a multivariate setting and then uses the estimated residuals to estimate the timevarying volatility of the two markets under consideration and their dynamic conditional correlations. This methodology will allow us to discuss our findings related to price linkages between oil and each stock and to focuses on their mean and volatility spillover effects.

\section{A. Fractional cointegration}

In this section we present the fractional cointegration model used to examine linkages between oil and each stock market. Per Davidson (2002, 2005) and Davidson et al. (2006), we develop an alternative approach to deal with multivariate fractionally integrated processes which use the parametric bootstrap to test the existence of cointegration. Davidson (2002) generalizes the model proposed by Granger (1986) by allowing the integration orders of the series to take different values $d_{i}, i=1, \ldots, k$.

$$
\left\{\begin{array}{l}
{\left[C(L)+\alpha \beta^{\prime}\left(K(L)^{-1}-I\right)\right] \Delta(L)\left(X_{t}+\Phi D_{t}\right)=\varepsilon_{t}} \\
K(L)=\operatorname{diag}\left\{(1-L)^{b_{1}}, \ldots,(1-L)^{b_{k}}\right\} ; \quad 0 \leq b_{i} \leq d_{i} \\
\Delta(L)=\operatorname{diag}\left\{(1-L)^{d_{1}}, \ldots,(1-L)^{d_{k}}\right\} ; \quad d_{1}, d_{2}, \ldots, d_{k} \geq 0
\end{array}\right.
$$

Here, $X_{t}(k \times 1)$ is a vector of observed variables, $D_{t}(\kappa \times 1)$ is a vector of exogenous variables, typically dummies, $\Phi(k \times \kappa)$ is a matrix of coefficients. $\varepsilon_{t}(k \times 1)$ is a vector of error terms, $\varepsilon_{t}$ will be assumed i.i.d. $(0, \Sigma)$, and $C(L)(k \times k)$ is a finite-order polynomial matrix in the lag operator with all roots outside the unit circle, which captures the short run effects. $\alpha$ and $\beta$ are constant matrices of dimension $(k \times r)$, which represent the error 
correction and cointegration coefficients, respectively. The equilibrium relationship is obtained; i.e., the set of variables are to be cointegrated if $\beta^{\prime} \Delta(L) K(L)^{-1}\left(X_{t}+\Phi D_{t}\right)$ is $I(0)$. Moreover, our study distinguishes the different orders of fractional integration. More precisely, the Regular Fractional Cointegration Model (RFCM) is defined as:

$$
\left[C(L) \Delta(L)-\alpha \beta(L)^{\prime} L\right]\left(X_{t}+\Phi D_{t}\right)=\varepsilon_{t}
$$

The Generalized Fractional Cointegration Model (GFCM) is given by:

$$
\left[C(L) \Delta(L)-\alpha \beta(L)^{\prime} L\right]\left(X_{t}+\Phi D_{t}\right)=\varepsilon_{t}
$$

In this equation, $\alpha(L)=\left\{\alpha_{i j}(L)\right\}$ and $\beta$ (resp. $\alpha$ and $\beta(L)=\left\{\beta_{i j}(L)\right\}$ ) for all $1 \leq j \leq r$ and $1 \leq j \leq r$ are matrices of dimension $k \times r$, and where $\alpha_{i j}(L)=\alpha_{i j}(1-L)^{d_{i}-b_{i j}}$ and $\beta_{i j}(L)=\beta_{i j}(1-L)^{d_{i}-b_{i j}}$. In order to determine the rank of the cointegrating system, the method proposed by Nielson and Shimotsu (2007) is used. ${ }^{3}$

\section{B. Conditional volatility and dynamic conditional correlations}

In this section we focus on the volatility spillover between the oil and stock markets. Our approach is based on a multivariate GARCH process to model the conditional variance. We use the DCC-GARCH model of Engle (2002) to estimate the timevarying volatility of crude oil and stock markets as well as their dynamic conditional correlations. This model extends the CCC-GARCH model of Bollerslev (1990) whereby the conditional correlations are assumed to be constant. In our study, the conditional mean of the DCC-GARCH model follows the generalized fractional cointegration process as described in Equation (1) and the conditional variance-covariance matrix, $H_{t}=E\left(\varepsilon_{t} \varepsilon_{t}^{\prime} \mid \Psi_{t-1}\right)$ with $\varepsilon_{t}=\left(\varepsilon_{1 t}, \ldots, \varepsilon_{k t}\right)^{\prime}=H_{t}^{1 / 2} \eta_{t}$ where $\eta_{t} \sim N\left(0, I_{k}\right)$, is modeled as:

\footnotetext{
${ }^{3}$ Nielson and Shimotsu (2007) extended the Robinson and Yajima (2002) procedure to accommodate both stationary and nonstationary fractionally integrated processes.
} 


$$
\left\{\begin{array}{l}
H_{t}=D_{t} R_{t} D_{t} \\
D_{t}=\operatorname{diag}\left(\sqrt{h_{1, t}}, \ldots, \sqrt{h_{k, t}}\right) \\
R_{t}=\operatorname{diag}\left(q_{11, t}^{-1 / 2}, \ldots, q_{k k, t}^{-1 / 2}\right) Q_{t} \operatorname{diag}\left(q_{11, t}^{-1 / 2}, \ldots, q_{k k, t}^{-1 / 2}\right) \\
Q_{t}=\left(1-\theta_{1}-\theta_{2}\right) \bar{Q}+\theta_{1} \eta_{t-1} \eta_{t-1}^{\prime}+\theta_{2} Q_{t-1} \\
\eta_{t}^{*}=\operatorname{diag}\left\{Q_{t}\right\}^{1 / 2} \eta_{t}
\end{array}\right.
$$

Here, $X_{t}$ is a $(k \times 1)$ vector of the system series, $\varepsilon_{t}$ is the vector of error terms estimated from the conditional mean equations, $H_{t}$ is the conditional variance-covariance matrix of system variables, $D_{t}$ is the $(k \times k)$ diagonal matrix of time-varying standard deviations computed from a univariate GARCH model, and $R_{t}$ is the $(k \times k)$ symmetric matrix of dynamic conditional correlations. $Q_{t}=\left(q_{i j t}\right)$ is a symmetric positive define matrix which is assumed to vary according to a GARCH-type process with $\bar{Q}$ being a $(k \times k)$ unconditional variance matrix of standardized residuals $\eta_{i, t}$. The parameters $\theta_{1}$ and $\theta_{2}$ are scalar parameters that capture the effects of shocks to dynamic correlations. $\theta_{1}$ and $\theta_{2}$ are non-negative and satisfy the condition $\theta_{1}+\theta_{2}<1$. The correlation estimator between variable $i$ and variable $j$ in the matrix $R_{t}$ is defined as follows:

$$
\rho_{i j, t}=\frac{q_{i j, t}}{\sqrt{q_{i i, t} q_{j j, t}}}
$$

Aielli (2008) proposes a corrected Dynamic Conditional Correlation (c-DCC) modeling in order to correct both the lack of consistency and the potential bias in the estimated parameters of the DCC-GARCH model of Engle (2002).

It is worth noting that we use the univariate FIAPARCH of Tse (1998) to model the conditional volatility of each of the system variables and then compute their time-varying standard deviations. This model is the extension of the APARCH model of Ding et al.(1993) and allows for the asymmetric responses of volatility to positive and negative shocks as well as the long memory property of conditional volatility. The FIAPARCH model is expressed as a power transformation of the conditional standard deviation as follows:

$$
h_{i, t}^{\delta_{i} / 2}=\omega_{i}+\left\{1-\left(1-\psi_{i}(L)\right)^{-1} \phi_{i}(L)(1-L)^{d_{v_{i}}}\right\}\left(\left|\varepsilon_{i, t}\right|-\gamma_{i} \varepsilon_{i, t}\right)^{\delta_{i}}
$$


Fractional degree of integration of $h_{i, t}$, and $\psi_{i}(L)$ and $\phi_{i}(L)$ the lag polynomials of the respective orders $P$ and $K$. The model assumes that $-1<\gamma_{i}<1$ and $\delta_{i}>0$. The power term $h_{i, t}^{1 / 2}$ plays the role of a Box-Cox transformation of the conditional standard deviation $h_{i, t}^{1 / 2}$, while $\gamma_{i}$ denotes the asymmetry coefficient accounting for the leverage effect. When $\gamma_{i}>0$, negative shocks have more impact on conditional volatility than positive shocks do. When $\gamma_{i}<0$, the magnitude of the shocks is captured by the term $\left(\left|\varepsilon_{i, t}\right|-\gamma \varepsilon_{i, t}\right)$.

\section{Data}

We use daily data for oil prices and stock market indices. Since our objective is to illustrate the usefulness of the empirical modeling strategy, our sample consists of only two oil-importing countries, France and the US. As of the end of 2012, these two countries are ranked $7^{\text {th }}$ and $1^{\text {st }}$ among the world's top net oil-importers with 7,445 and 1,668 thousand barrels per day, respectively. The difference between these two countries in terms of oil-dependence levels will enable us to shed light on the specific oil-stock market relationships for these two countries.

We use the CAC40 index and the Dow Jones Industrial Average (DJA) index to represent the overall performance of the French and US stock markets. For oil prices, we consider the Brent crude oil price benchmark as it accounts for $65 \%$ of the world's daily oil production and is used to price two-thirds of the world's internationally traded crude oil supplies. Daily data from January 1, 1999 to December 17, 2012 are expressed in US dollars, oil prices are extracted from the Federal Reserve Bank of Saint Louis, and stock market indices from Datastream International. Our study period thus overlaps several periods of extreme movements in both crude oil and stock markets, such as the September 11 terrorist attack in the United States, the 2007 US subprime crisis, the global financial crisis of 2008 2009, and the political unrest in the Middle East and North Africa (MENA) countries. 
Table 1. Summary statistics

\begin{tabular}{|c|c|c|c|}
\hline & DLOil & DLCAC & DLDJI \\
\hline Mean & $0.6506 \times 10^{-3}$ & $-0.0487 \times 10^{-3}$ & $0.1105 \times 10^{-3}$ \\
\hline Standard deviation & 0.0236 & 0.0154 & 0.0124 \\
\hline Skewness & $\begin{array}{l}-0.2176 \\
{[0.1446]}\end{array}$ & $\begin{array}{l}-0.3872 \\
{[0.0094]}\end{array}$ & $\begin{array}{l}-0.0459 \\
{[0.7580]}\end{array}$ \\
\hline Excess kurtosis & $\begin{array}{c}0.0657 \\
{[0.8249]}\end{array}$ & $\begin{array}{c}0.5656 \\
{[0.0567]}\end{array}$ & $\begin{array}{c}0.1149 \\
{[0.7127]}\end{array}$ \\
\hline Jarque-Bera & $\begin{array}{l}2.1524 \\
{[0.3409]}\end{array}$ & $\begin{array}{c}10.2367^{*} \\
{[0.0059]}\end{array}$ & $\begin{array}{c}0.2269 \\
{[0.8927]}\end{array}$ \\
\hline$Q(20)$ & $\begin{array}{c}57.0254 * * * \\
{[0.0000]}\end{array}$ & $\begin{array}{c}69.2921 * * * \\
{[0.0000]}\end{array}$ & $\begin{array}{c}72.4929 * * * \\
{[0.0000]}\end{array}$ \\
\hline $\mathrm{ARCH}(10)$ & $\begin{array}{c}39.1435 * * * \\
{[0.0000]}\end{array}$ & $\begin{array}{c}73.4682 * * * \\
{[0.0000]}\end{array}$ & $\begin{array}{c}86.5471 * * * \\
{[0.0000]}\end{array}$ \\
\hline
\end{tabular}

(Note) $*$, **, and *** indicate that the null hypothesis of normality, no autocorrelation, and no ARCH effect is rejected at the $10 \%, 5 \%$, and $1 \%$ rate respectively. $p$-values of statistic tests are in brackets.

Return series are computed by taking the difference in the logarithm (DL) of two consecutive prices. Summary statistics of both price and return series are given in Table 1. Using Ljung-Box test ARCH-LM test, we can see all the price series are characterized by a symmetric and fatted-tail behavior, as well as serial correlation and conditional heteroscedasticity. The presence of these stylized facts thus justifies our choice of combining the multivariate fractionally integrated process and the multivariate GARCHtype model.

\section{Empirical Findings}

\section{A. Integration order and cointegration relationships}

We begin with the identification of the order of integration of each of the price series 
in logarithm under consideration of oil price, CAC40 index, and DJIA index by using the two-step Exact Local Whittle (ELW) estimator of Shimotsu (2010). This estimator is based on the modified ELW objective function and uses a tapered estimator of Shimotsu and Phillips (2005). The two-step ELW estimator is more advantageous than the standard ELW estimator in that it allows for an unknown mean and polynomial time trend. Shimotsu (2010) shows that the two-step estimator FELW $\left(\hat{d}_{F E L W}\right)$ is consistent and that under certain assumptions, regularization admits a normal limit distribution $N(0,1 / 4)$ for $d \in(-1 / 2,7 / 4)$ or $d \in(-1 / 2,7 / 4)$ when the data has a polynomial trend. The estimation results for the log price series, reported in Table 2, indicate that all the price series are characterized by a fractional integrated process.

Table 2. Fractional integration orders

\begin{tabular}{|c|c|c|c|c|}
\hline & \multicolumn{3}{|c|}{$\hat{d}_{F E L W}$} & \multirow{2}{*}{$\bar{d}_{*}=\frac{1}{3} \sum_{i=1}^{3} \hat{d}_{F E L W}$} \\
\hline Bandwidth & $\begin{array}{c}\text { Oil prices, } \\
\ln (\text { Oil) }\end{array}$ & $\begin{array}{c}\text { CAC40 stock } \\
\text { market index, } \\
\ln (\text { CAC40) }\end{array}$ & $\begin{array}{c}\text { Dow Jones } \\
\text { Industrial Average } \\
\text { Index, ln(DJI) }\end{array}$ & \multirow{2}{*}{1.033} \\
\hline$m=\left[T^{0.6}\right]$ & $\begin{array}{c}1.065^{* * *} \\
(0.085)\end{array}$ & $\begin{array}{c}1.058^{* * *} \\
(0.085)\end{array}$ & $\begin{array}{c}0.977 * * * \\
(0.085)\end{array}$ & 1.057 \\
\hline$H_{i j}: d_{i}=d_{j}$ & $\begin{array}{c}1.159 * * * \\
(0.127)\end{array}$ & $\begin{array}{c}1.055^{*} * * \\
(0.127)\end{array}$ & $\begin{array}{c}0.957 * * * \\
(0.127)\end{array}$ & \multirow{2}{*}{}
\end{tabular}

(Note) Standard errors are given in parentheses, a nonzero mean was allowed in the estimation. ${ }^{* * *}$ represents significance at the $1 \%$ level.

We then test the equality of the orders of integration of the price series in order to determine the potential of cointegration relationships. If the series are integrated of the same order, there exists at least one cointegrating relationship. Otherwise, we have to examine the equality of integration order for pairs of price series. The null hypotheses are: $H_{0}: d_{i}=d_{*}, i=1,2,3$ and $H_{i j}: d_{i}=d_{j}$, where $d_{*}$ is a certain value of $d$. Under these hypotheses, two corresponding empirical statistics, $\hat{T}_{0}$ and $\hat{T}_{i j}$, are defined by Robinson and Yajima (2002) to test $H_{0}$ and $H_{i j}$. Moreover, under the assumptions given in

Nielson and Shimotsu (2007), we have: $\hat{T}_{0} \rightarrow x^{2}(k-1)$ and $\hat{T}_{i j} \rightarrow N(0,1)^{4}$.

When $m=\left[T^{0.6}\right]$, the values of the $\hat{T}_{0}$ statistic are equal to 1.534 and 3.038 if the

${ }^{4}$ Robinson and Yajima (2002) and Nielson and Shimotsu (2007) for more details. 
bandwidth is equal to $(\log (T))^{-2}$ and $(\log (T))^{-2}$ respectively. When $m=\left[T^{0.5}\right], \hat{T}_{0}$ statistic takes the values 1.607 and 2.935, with $(\log (T))^{-2}$ and $(\log (T))^{-2}$ respectively. Given these values of $\hat{T}_{0}$ statistic, the null hypothesis of equality of the integration orders cannot be rejected. As a result, the common integration order $\bar{d}_{*}$ can be used to estimate the eigenvalues of $\hat{G}\left(\bar{d}_{*}\right)$ and $\hat{P}\left(\bar{d}_{*}\right)$ as advanced by Nielson and Shimotsu (2007), while allowing for a nonzero mean. The obtained results, presented in Table 3, show that some eigenvalues $\hat{\delta}_{i}, i=1,2,3$ could have a zero value, suggesting the existence of at least one cointegrating relationship between the series we consider.

The next step consists of determining the cointegrating rank $r$ of the series using the model selection procedure with $\hat{P}\left(\bar{d}_{*}\right){ }^{6}$. The obtained results, displayed in Table 4, clearly show evidence of the presence of one cointegrating relationship $(\hat{r}=1)$ among the three variables under consideration, which suggests the suitability of the fractional cointegration process in modeling the dynamics of log price series.

Table 3. Eigenvalues for $\log$ price series

\begin{tabular}{|c|c|c|c|}
\hline Bandwidth & $\hat{\delta}_{1}$ & $\hat{\delta}_{3}$ & $\hat{\delta}_{3}$ \\
\hline \multicolumn{4}{|c|}{ Eigenvalues of $10^{4} \times \hat{G}\left(\bar{d}_{*}\right)$} \\
\hline$m_{1}=\left[T^{0.45}\right]$ & 0.939 & 0.373 & 0.042 \\
\hline$m_{1}=\left[T^{0.45}\right]$ & 1.406 & 0.314 & 0.032 \\
\hline \multicolumn{5}{|c|}{ Eigenvalues of $\hat{P}\left(\bar{d}_{*}\right)$} \\
\hline$m_{1}=\left[T^{0.55}\right]$ & 1.876 & 0.939 & 0.195 \\
\hline$m_{1}=\left[T^{0.45}\right]$ & 1.897 & 0.927 & 0.175 \\
\hline
\end{tabular}

\footnotetext{
${ }^{5}$ The matrix $\hat{G}\left(\bar{d}_{\text {. }}\right)$ is calculated by considering a new bandwidth $m_{1}$, chosen such that $m / m_{1} \rightarrow 0$.

${ }^{6}$ The model selection procedure performs better when it is based on $\hat{P}\left(\bar{d}_{*}\right)$ than $\hat{G}\left(\bar{d}_{*}\right)$. Nielson and Shimotsu (2007) for more details.
} 
Table 4. Rank of cointegration

\begin{tabular}{|c|c|c|c|c|c|}
\hline$L(u)$ & $v(T)=m_{1}^{-0.45}$ & $v(T)=m_{1}^{-0.35}$ & $v(T)=m_{1}^{-0.15}$ & $v(T)=m_{1}^{-0.15}$ & $v(T)=m_{1}^{-0.05}$ \\
\hline \multicolumn{6}{|c|}{$m_{1}=\left[T^{0.55}\right], m=\left[T^{0.6}\right]$} \\
\hline$L(0)$ & -2.598 & -2.372 & -2.018 & -1.465 & -0.601 \\
\hline$L(1)$ & -2.537 & -2.386 & -2.151 & -1.782 & -1.206 \\
\hline$L(2)$ & -1.742 & -1.666 & -1.548 & -1.364 & -1.075 \\
\hline$\hat{r}$ & 0 & 1 & 1 & 1 & 1 \\
\hline \multicolumn{6}{|c|}{$m_{1}=\left[T^{0.45}\right], m=\left[T^{0.5}\right]$} \\
\hline$L(0)$ & -2.416 & -2.160 & -1.792 & -1.263 & -0.499 \\
\hline$L(1)$ & -2.435 & -2.265 & -2.019 & -1.665 & -1.157 \\
\hline$L(2)$ & -1.702 & -1.6171 & -1.494 & -1.318 & -1.063 \\
\hline$\hat{r}$ & 1 & 1 & 1 & 1 & 1 \\
\hline
\end{tabular}

(Note) The model selection procedure determines $\hat{r}$ as the $\arg \min L(u)$, and the calculation of $L(u)$ allowed for a nonzero mean where $L(u)=v(T)(k-u)-\sum_{i=1}^{k-u} \hat{\delta}_{i}$ with $v(T)>0$ and $\lim _{T \rightarrow \infty} v(T)+m_{1}^{-1 / 2} v(T)^{-1}=0$.

\section{B. Results}

The results we presented in the previous section suggest the existence of one possible cointegrating relationship between oil prices and stock price indices in France and the US. Therefore, a RFCM as defined by Equation (2) or a GFCM as defined by Equation (3) can be used to reproduce the short-term and long-term dynamics among the system variables. The choice between these two models relies on the estimation of the GFCM and the validation of some assumptions which are essential to the acceptance of the cointegrating relationship. At the estimation level, the bootstrap method developed by Davidson $(2002,2005,2006)$ is helpful in correcting the distortions of the significance levels owing to the fact that the asymptotic distribution under the null hypothesis depends on a nuisance parameter. In our study, the Schwarz and Hannan-Quinn (HQ) information criteria and the Li and McLeod (1981)'s multivariate modified portmanteau test statistic select one lag $(p=1)$ for the fractional cointegration process.

The obtained results for the RFCM, given by Equation (2), indicate that the hypotheses 
of nullity of the model parameters $\left(\alpha_{i}\right.$ and $\left.\beta_{i}\right)$ cannot be rejected at conventional levels for all the series of interest. ${ }^{7}$ Moreover, the null hypothesis $H_{0}: b_{1}=b_{2}=b_{3}=b$ is rejected at high levels. This finding thus suggests the absence of cointegration relationship between the series and that a regular fractional cointegration model seems not to be an adequate specification for our data. For this reason, we check the suitability of a generalized fractional cointegration model whereby the variables can have the different orders of integration. This specification allows for more flexibility in the model estimation since it does not impose any restrictions on the movement and dynamic components among the variables. The system of equations of the GFCM model, given by Equation (3) for $p=1$, can be written as follows:

$$
\begin{aligned}
& (1-L)^{\widehat{d}_{1}} x_{1 t}=\widehat{\alpha}_{1}\left((1-L)^{\hat{d}_{1}-\hat{b}_{1}} x_{1, t-1}-\widehat{\beta}_{2}(1-L)^{\widehat{d}_{2}-\hat{b}_{2}} x_{2, t-1}-\widehat{\beta}_{3}(1-L)^{\hat{d}_{3}-\widehat{b}_{3}} x_{3, t-1}\right) \\
& +(1-L)^{\hat{d}_{1}}\left(\widehat{\gamma}_{11} x_{1, t-1}-\widehat{\gamma}_{12} x_{2, t-1}-\widehat{\gamma}_{13} x_{3, t-1}-c\right)+\varepsilon_{1 t} \\
& (1-L)^{\hat{d}_{2}} x_{2 t}=\widehat{\alpha}_{2}\left((1-L)^{\hat{d}_{1}-\widehat{b}_{1}} x_{1, t-1}-\widehat{\beta_{2}}(1-L)^{\hat{d}_{2}-\hat{b}_{2}} x_{2, t-1}-\widehat{\beta}_{3}(1-L)^{\hat{d}_{3}-\hat{b}_{3}} x_{3, t-1}\right) \\
& +(1-L)^{\hat{d}_{2}}\left(\widehat{\gamma}_{21} x_{1, t-1}-\widehat{\gamma}_{22} x_{2, t-1}-\widehat{\gamma}_{23} x_{3, t-1}-c\right)+\varepsilon_{2 t} \\
& (1-L)^{\hat{d}_{3}} x_{3 t}=\widehat{\alpha_{3}}\left((1-L)^{\hat{d}_{1}-\hat{b}_{1}} x_{1, t-1}-\widehat{\beta}_{2}(1-L)^{\hat{d}_{2}-\hat{b}_{2}} x_{2, t-1}-\widehat{\beta}_{3}(1-L)^{\hat{d}_{3}-\hat{b}_{3}} x_{3, t-1}\right) \\
& +(1-L)^{\hat{d}_{3}}\left(\widehat{\gamma}_{31} x_{1, t-1}-\widehat{\gamma}_{32} x_{2, t-1}-\widehat{\gamma}_{33} x_{3, t-1}-c\right)+\varepsilon_{3 t}
\end{aligned}
$$

Here, $x_{1 t}, x_{2 t}$, and $x_{3 t}$ represent the logarithm of oil prices (LOIL), CAC40 stock market index (LCAC), and Dow Jones Industrial Average Index (LDJI). $\hat{\beta}_{i}$ refers to the equilibrium relationship coefficient, $\hat{\alpha}_{i}$ the short-term component, $\hat{d}_{i}$ the long memory parameter for the $x_{i t}$ variable, $\hat{b}_{i}$ a parameter satisfying the condition $0<b_{i} \leq d_{i}$, and $\hat{\gamma}_{i j}$ the coefficients of the lagged terms.

Table 5 reports the estimation results for the GFCM. Accordingly, the values of the fractional integration parameter $d_{i}$ lies between $1 / 2$ and 1 . We also observe that the estimated values for $b_{i}$ are smaller than the estimated $d_{i}$ verifying the condition $d_{i}-b_{i}>0$. However, $\hat{\alpha}_{i}$ has a negative sign, implying that the price series under consideration have a decreasing tendency in the short run. Another important fact is the significant effect of past realizations on the current values of the price series.

A Fisher test is then used to validate the existence of a cointegration relationship

${ }^{7}$ The results are not reported here for concision purpose, but they can be made entirely available under request. 
between oil prices and stock market indices. The empirical results, reported in Table 6, indicate that the hypotheses of nullity of the parameters of the GFCM are rejected. Thus, the LOIL, the LCAC, and the LDJI series move together to a long-run stable equilibrium. It is worth noting that the estimation of the GFCM model also allows one to assess the sustainable unidirectional causality in the long run (Granger 1988), as opposed to shortterm causal relationships (Granger 1969). In this context, reverse causality can intervene as soon as a sustainable current variable is defined as the expectation of future variables. 
Table 5. The Generalized fractional cointegration model

\begin{tabular}{|c|c|c|c|}
\hline & $\ln (\mathrm{Oil})$ & $\ln (C A C 40)$ & $\ln (D J I)$ \\
\hline$d_{i}$ & $\begin{array}{c}0.995 \\
(26.365)^{* * * *}\end{array}$ & $\begin{array}{c}0.982 \\
(5.097)^{* * *}\end{array}$ & $\begin{array}{c}0.942 \\
(9.842)^{* * *}\end{array}$ \\
\hline$b_{i}$ & $\begin{array}{c}0.251 \\
(6.557)^{* * *}\end{array}$ & $\begin{array}{c}0.296 \\
(5.419) * * *\end{array}$ & $\begin{array}{c}0.448 \\
(4.661)^{* * *}\end{array}$ \\
\hline$\alpha_{i}$ & $\begin{array}{c}-0.038 \\
(-6.518) * * *\end{array}$ & $\begin{array}{c}-0.028 \\
(-4.109) * * *\end{array}$ & $\begin{array}{c}-0.167 \\
(-4.453) * * *\end{array}$ \\
\hline$\beta_{i}$ & 1 & $\begin{array}{c}-3.280 \\
(-7.373) * * *\end{array}$ & $\begin{array}{c}-3.236 \\
(-11.068) * * *\end{array}$ \\
\hline$c$ & $\begin{array}{c}2.192 \\
(5.471)^{* * *}\end{array}$ & $\begin{array}{c}9.006 \\
(3.745) * * *\end{array}$ & $\begin{array}{c}9.378 \\
(7.907)^{* * *}\end{array}$ \\
\hline$\gamma_{1 i}$ & $\begin{array}{c}-0.013 \\
(1.914) * *\end{array}$ & $\begin{array}{c}0.115 \\
(1.436)^{*}\end{array}$ & $\begin{array}{c}0.152 \\
(1.667) * *\end{array}$ \\
\hline$\gamma_{2 i}$ & $\begin{array}{c}0.011 \\
(2.051)^{* *}\end{array}$ & $\begin{array}{c}-0.227 \\
(-1.504) *\end{array}$ & $\begin{array}{c}0.482 \\
(11.188)^{* * *}\end{array}$ \\
\hline$\gamma_{3 i}$ & $\begin{array}{c}0.006 \\
(1.759)^{* *}\end{array}$ & $\begin{array}{c}-0.021 \\
(3.578) * * *\end{array}$ & $\begin{array}{c}-0.025 \\
(4.327)^{* * *}\end{array}$ \\
\hline Skewness & -0.250 & -0.090 & 0.123 \\
\hline Kurtosis & $7.843 * * *$ & $5.419 * * *$ & $6.314 * * *$ \\
\hline Jarque-Bera & $366.577 * * *$ & $609.899 * * *$ & $185.286^{* * *}$ \\
\hline Adjusted $\mathrm{R}^{2}$ & 0.998 & 0.995 & 0.990 \\
\hline $\mathrm{Q}(20)$ & 21.115 & 16.441 & 27.789 \\
\hline $\mathrm{Q}^{2}(20)$ & $617.789 * * *$ & $541.431 * * *$ & $985.311 * * *$ \\
\hline \multicolumn{4}{|c|}{$\begin{array}{c}\text { Schwarz: } 7059.690 \\
\text { Hannan-Quinn: } 7122.763 \\
Q_{(L-M)}(20)^{8}: 198.533 \\
\text { Log-Likelihood: } 7189.832\end{array}$} \\
\hline
\end{tabular}

(Note) $t$-statistics are given in parentheses. $* * *, * *$, and $*$ denote significance at $1 \%, 5 \%$, and $10 \%$ statistical levels respectively. $\hat{\beta}_{i}$ refers to the equilibrium relationship coefficient.

\footnotetext{
${ }^{8} Q_{(L-M)}$ is the multivariate modified portmanteau test statistic suggested bay Li and McLeod (1981). The asymptotic distributions of $Q_{m}^{(L-M)}$ is chi-squared with 180 degrees of freedom.
} 
Table 6. Validation of the generalized fractional cointegration model

\begin{tabular}{|l|c|c|c|}
\hline \multicolumn{4}{|c|}{$F_{\text {statistics }}$} \\
\hline Bootstrap & Regular & Double & Fast-Double \\
\hline$H_{0}: \alpha_{1}=\alpha_{2}=\alpha_{3}=0$ & 0.003 & 0.002 & 0.001 \\
\hline$H_{0}: \beta_{1}=\beta_{2}=\beta_{3}=0$ & 0.006 & 0.003 & 0.002 \\
\hline$H_{0}: \alpha_{i}=\beta_{i}=0$ & 0.002 & 0.001 & 0.000 \\
\hline$H_{0}: b_{i}>0, i=1,2,3$ & 0.002 & 0.000 & 0.000 \\
\hline$H_{0}: d_{i}-b_{i}>0, i=1,2,3$ & 0.001 & 0.000 & 0.000 \\
\hline
\end{tabular}

(Note) This table reports the $p$-values of the Fisher test for all hypothesis $H_{0}$ which aims to examine whether there is a cointegrating relationship between the variables of interest. $\hat{\alpha}_{i}, \hat{\beta}_{i}, \hat{b}_{i}$ and $\hat{b}_{i}$ represent the short-term component, the equilibrium relationship coefficient, the long memory parameter, and a parameter satisfying the condition $0<b_{i}<d_{i}$.

Figure 1 plots the actual price series of crude oil and stock market indices as well as the resifual series we obtained from estimating the GFCM model. The logarithm of brent crude oil price from January 1999 to December 2012 appear to demonstrate nonstationary behavior, in the sense that it does not converge towards its long-term means. 
Figure 1. Generalized fractional cointegration model
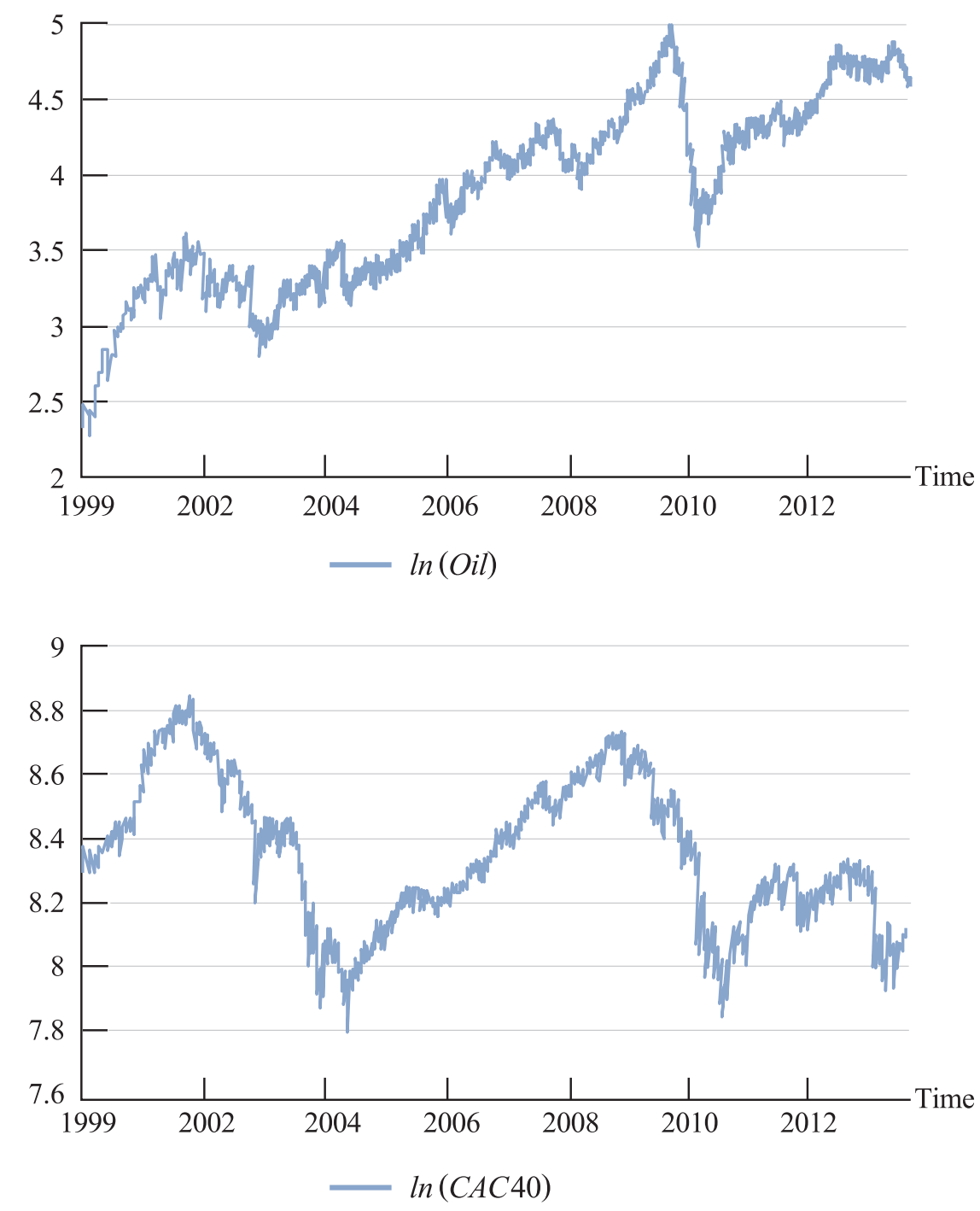

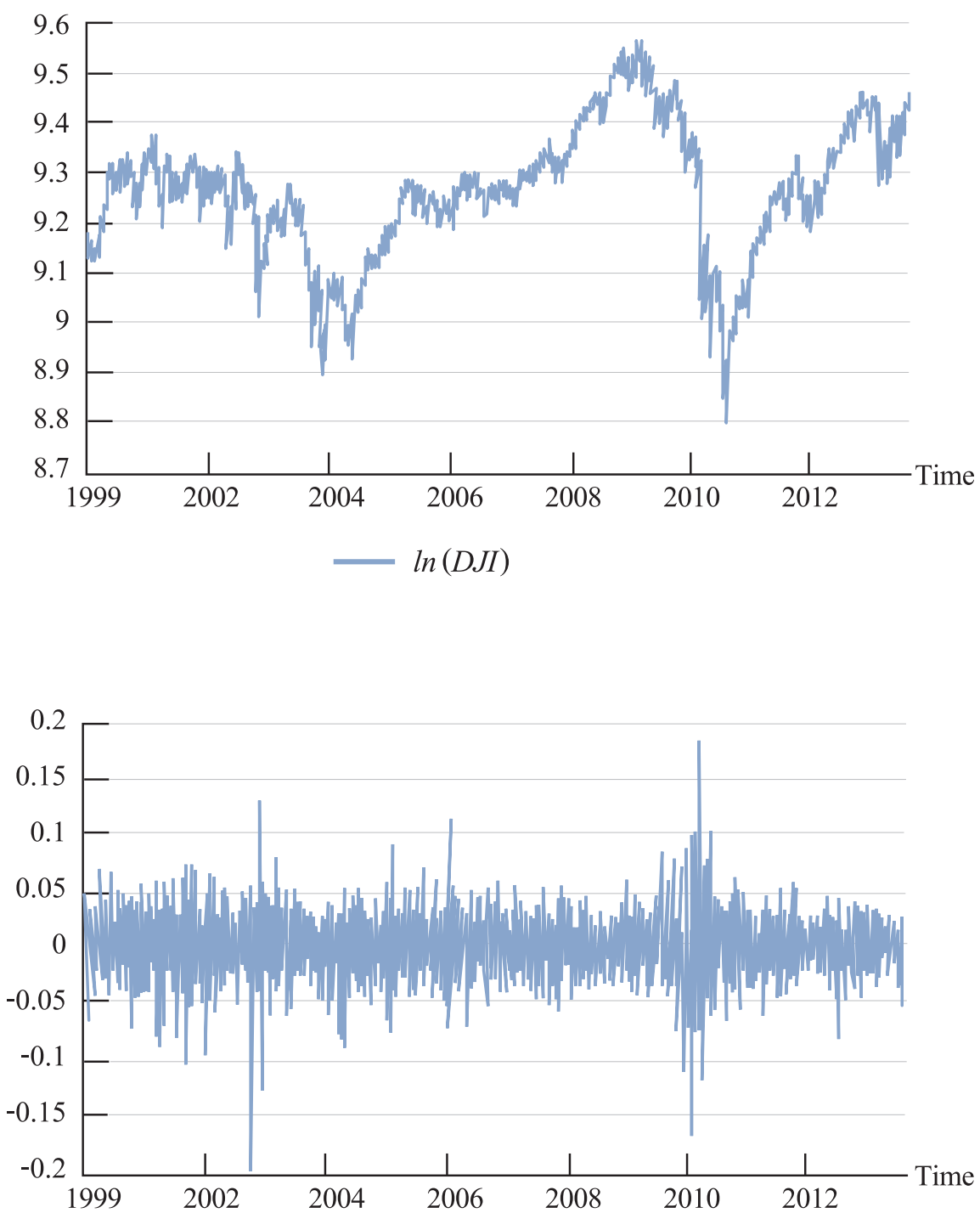

Residuals for $\ln (\mathrm{Oil})$ 


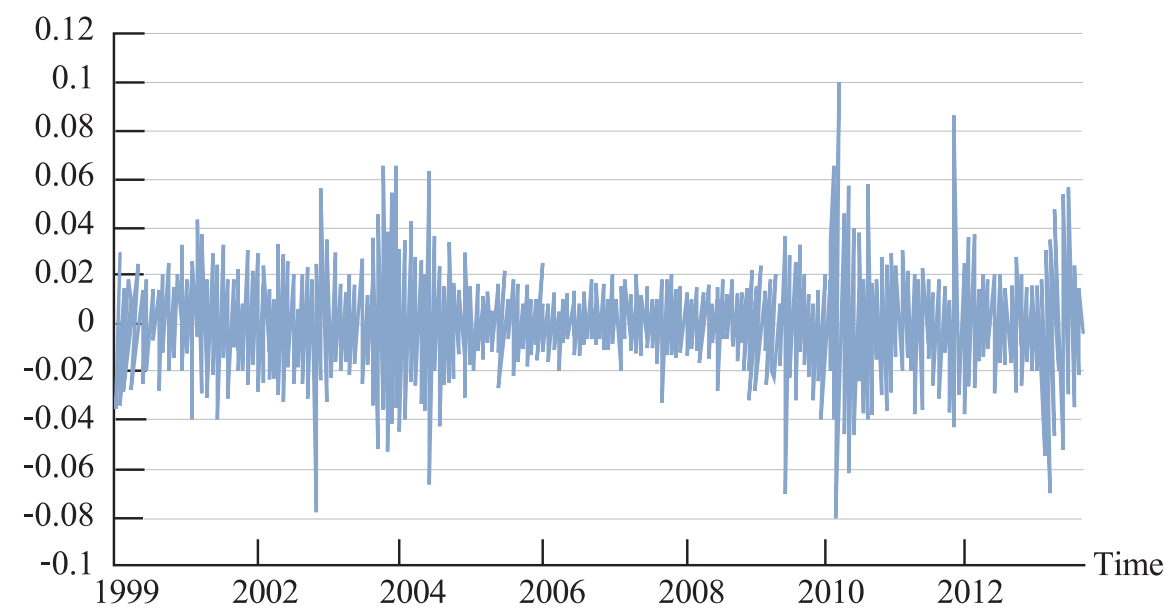

Residuals for $\ln (C A C 40)$

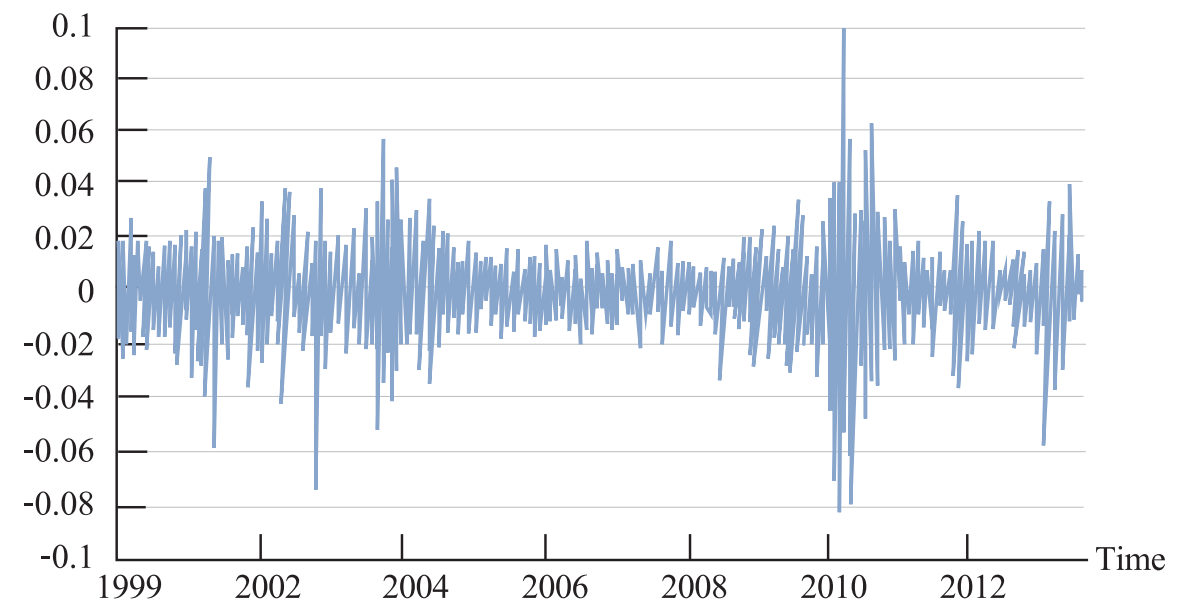

Residuals for $\ln (D J I)$ 
Figure 2. Correlograms of the absolute residuals

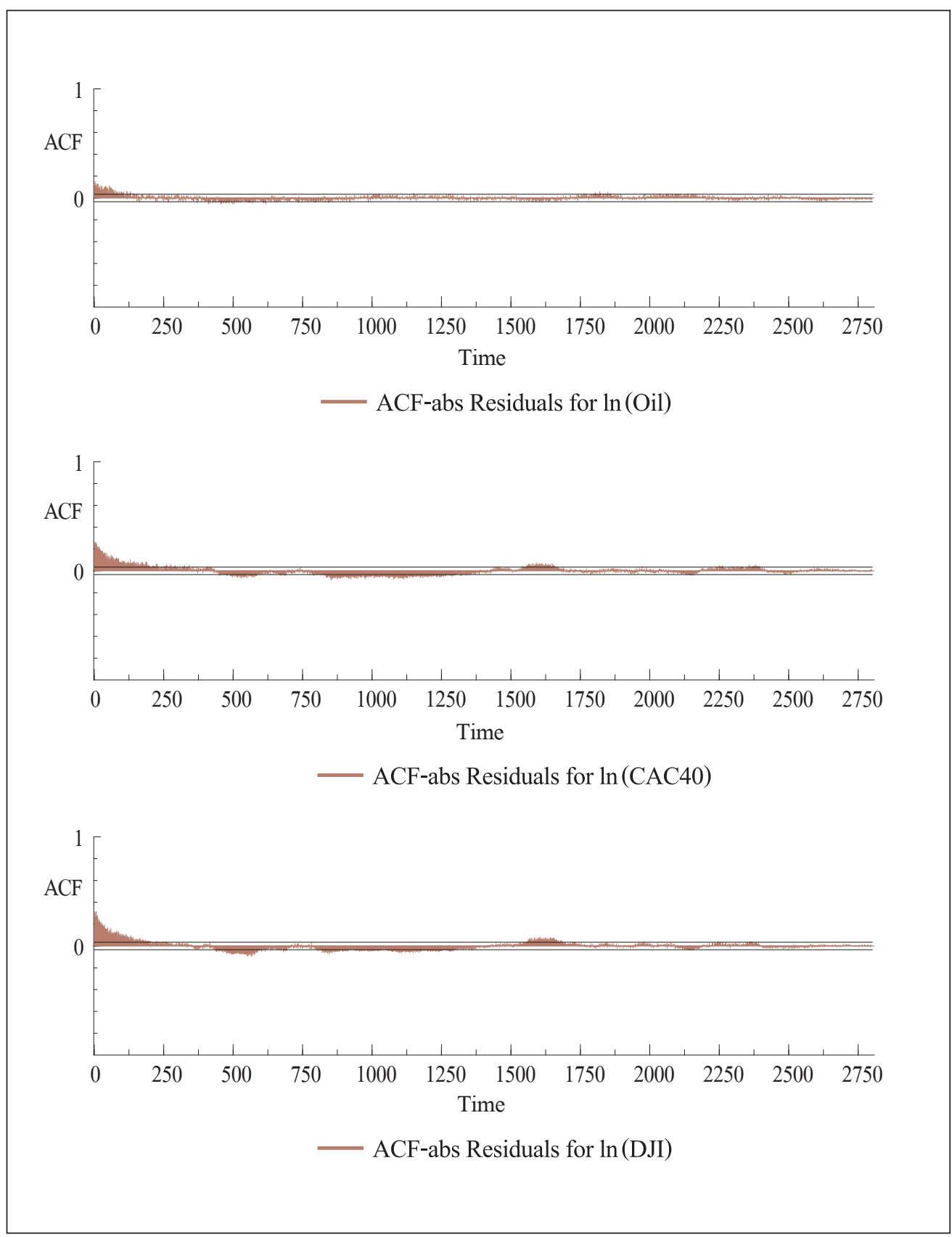




\section{Dynamic conditional correlations}

This section reports the results of the oil-stock market linkages estimated from combining the c-DCC-FIAPARCH with the generalized fractional cointegration model (Table 6). As stated earlier, the multivariate c-DCC-FIAPARCH framework is typically suitable for capturing the stylized facts of the oil and stock markets because it explicitly takes into account the volatility asymmetries and persistence. The Maximum Likelihood Estimation (MLE) as suggested by Davidson (2008) is used to carry out the estimation of the combined model. We firstly estimate the conditional volatility of individual series using univariate FIAPARCH models and then estimate the conditional correlations using the c-DCC specification.

The estimation results of the FIAPARCH model in Table 7 reveals several interesting facts. First, the power term of returns $\hat{\delta}$ is highly significant at the $1 \%$ level. This finding suggests that the volatility persistence is predictable. Second, the estimated asymmetry coefficient $\hat{\gamma}$ is significant and positive, implying that negative shocks have greater impact on volatility than positive shocks. We carried out a likelihood ratio test to examine the relevance of the restricted FIGARCH specification whereby $\delta_{\mathrm{i}}=2$ and $\gamma_{\mathrm{i}}=0$. The empirical $x^{2}$ test statistic with 2 degrees of freedom (under the null hypothesis that the restricted version holds) yields the values of 51.456, 43.125, and 33.867 respectively for residuals OIL, CAC, and DJI and clearly rejects the restricted version at $1 \%$ significance level $\left(x_{(2)}^{2}=9.210\right)$. 
Table 7. The c-DCC-FIAPARCH model

\begin{tabular}{|c|c|c|c|}
\hline First Step & $\begin{array}{l}\text { Equation (1) for } \\
\text { residuals of } \ln (\text { Oil) }\end{array}$ & $\begin{array}{c}\text { Equation (2) for } \\
\text { residuals of } \ln (\mathrm{CAC40)}\end{array}$ & $\begin{array}{l}\text { Equation (3) for } \\
\text { residuals of } \ln (\mathrm{DJI})\end{array}$ \\
\hline$\omega \times 10^{4}$ & $\begin{array}{l}87.076 \\
(1.651)^{*}\end{array}$ & $\begin{array}{c}37.056 \\
(1.987) * *\end{array}$ & $\begin{array}{c}58.684 \\
(3.161)^{* * *}\end{array}$ \\
\hline$d_{v}$ & $\begin{array}{c}0.317 \\
(7.560)^{* * *}\end{array}$ & $\begin{array}{c}0.459 \\
(10.661)^{* * *}\end{array}$ & $\begin{array}{c}0.369 \\
(9.960)^{* * *}\end{array}$ \\
\hline$\gamma$ & $\begin{array}{c}0.488 \\
(3.483)^{* * *}\end{array}$ & $\begin{array}{c}0.470 \\
(4.950)^{* * *}\end{array}$ & $\begin{array}{c}0.892 \\
(17.843)^{* * *}\end{array}$ \\
\hline$\delta$ & $\begin{array}{c}1.421 \\
(9.301)^{* * *}\end{array}$ & $\begin{array}{c}1.481 \\
(13.675)^{* * *}\end{array}$ & $\begin{array}{c}1.234 \\
(14.312)^{* * *}\end{array}$ \\
\hline$\psi$ & $\begin{array}{c}0.404 \\
(4.130)^{* * *}\end{array}$ & $\begin{array}{c}0.579 \\
(11.367)^{* * *}\end{array}$ & $\begin{array}{c}0.571 \\
(9.298)^{* * *}\end{array}$ \\
\hline$\phi$ & $\begin{array}{c}0.133 \\
(3.739)^{* * *}\end{array}$ & $\begin{array}{c}0.169 \\
(4.082)^{* * *}\end{array}$ & $\begin{array}{c}0.255 \\
(5.844)^{* * *}\end{array}$ \\
\hline Skewness & $\begin{array}{l}-0.246 \\
(6.039) * * *\end{array}$ & $\begin{array}{c}-0.169 \\
(4.029) * * *\end{array}$ & $\begin{array}{l}-0.392 \\
(9.355)\end{array}$ \\
\hline Kurtosis & $\begin{array}{c}4.362 \\
(16.242)^{* * *}\end{array}$ & $\begin{array}{c}3.479 \\
(5.718)^{* * *}\end{array}$ & $\begin{array}{c}3.409 \\
(16.807)^{* * *}\end{array}$ \\
\hline$Q(20)$ & 16.075 & 17.033 & 25.727 \\
\hline$Q^{2}(20)$ & 14.351 & 18.483 & 19.731 \\
\hline$B D S(5)$ & 2.943 & 1.587 & 1.974 \\
\hline Log-Likelihood & 8154.383 & 10161.407 & 10872.622 \\
\hline \multicolumn{4}{|c|}{ Second Step } \\
\hline$\theta_{1}$ & \multicolumn{3}{|c|}{$\begin{array}{c}0.007 \\
(4.078)^{* * *}\end{array}$} \\
\hline$\theta_{2}$ & \multicolumn{3}{|c|}{$\begin{array}{c}0.990 \\
(354.224)^{* * *}\end{array}$} \\
\hline$\rho_{21}$ & \multicolumn{3}{|c|}{$\begin{array}{c}-0.053 \\
(-8.213)^{* * *}\end{array}$} \\
\hline$\rho_{31}$ & \multicolumn{3}{|c|}{$\begin{array}{c}0.065 \\
(10.142)^{* * *}\end{array}$} \\
\hline$\rho_{32}$ & \multicolumn{3}{|c|}{$\begin{array}{c}0.581 \\
(13.541)^{* * *}\end{array}$} \\
\hline Log-Likelihood & \multicolumn{3}{|c|}{29884.697} \\
\hline
\end{tabular}

(Note) The student's $t$-statistics are indicated between brackets. ***,**, and * denote significance at $1 \%, 5 \%$, and $10 \%$ levels respectively. 
The correlations analyses unveil a few main trends (Figure 3). First, during the subperiod 2008 2010, the coefficients of correlation are generally positives. The main event of this phase is the global financial crisis initiated by the export of American mortgages to the rest of the world, such as asset-backed securities, which can be considered as an aggregate demand side oil shock (International Energy Agency 2009). This result is also supported by the analysis of Filis et al. (2011), who show that the positive correlation between oil prices and stock markets can be explained by the fact that the crisis has caused such a bearish stock market to enter the territories and oil prices to fall sharply. Second, a peak in correlation coefficient is observed around the year 2009. This high positive correlation between oil and stock market prices was initiated because of the high demand for oil due to the rapid increase in the housing market and construction industry, which was a result of decreasing interest rates worldwide. Hamilton (2009b), Kilian and Park (2009), and Filis et al. (2011) explain that the sub-period 2006 2009 is characterized by an increasing of oil prices due to rising demand by world economic growth. This aggregate demand-side oil price shock was expected to have a positive effect on oil importing countries. 
Figure 3. The conditional correlation

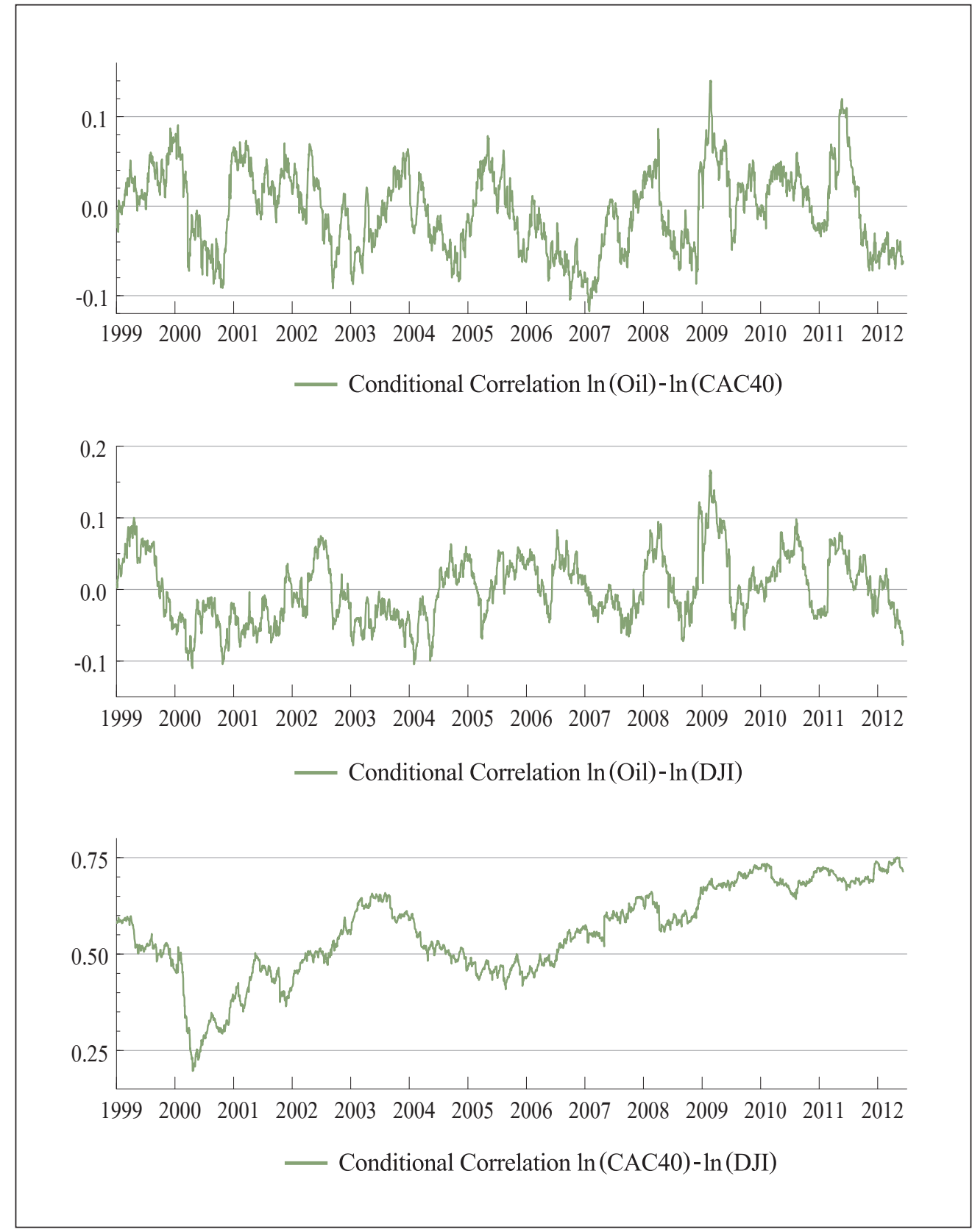

Oil price shocks in periods of world turmoil and political events have an important impact on the relationship between oil and stock market prices. Regarding the sign of this 
correlation, we find two trends: a negative one, as in Filis et al. (2011), Hamilton (2009a, 2009b) and Kilian and Park (2009), who argue that first and second wars in Iraq and the terrorist attack in the US tend to cause this negative correlation between oil and stock markets; and a positive one, when aggregate demand-side oil price shocks, which are Asian crisis, Chinese economic growth and the global financial crisis cause a significant positive correlation between stock market prices and oil prices. The repercussions of these phenomena are not symmetric in all the countries under consideration. Therefore we do not see a proper contagion effect. However, some specific trends appear among countries whose stock markets exhibit positive correlations.

\section{Conclusion}

A better understanding of the dynamic linkages between crude oil and stock markets is an important issue in the energy finance literature. Research in this direction allows one to investigate whether fluctuations in oil prices affect the movements in the stock price of listed companies. While an extensive literature has been devoted to this issue, none of the existing papers have considered the potential of fractional cointegration between oil and stock prices as well as its effects on the cross-market dynamic relationships.

Our study contributes to the previous literature by proposing a novel way to explore the oil-stock market linkages through a combination of the multivariate fractional cointegration and the c-DCC-FIAPARCH model. This integrated framework is particularly advantageous in that it allows one to model the joint dynamics of oil and stock markets over time while accommodating the transmission of return and volatility shocks across these markets, as well as their long-run causal links. The c-DCCFIAPARCH modeling also captures the long memory characteristic and asymmetry in the conditional volatility, as well as the heterogeneity problem of correlation behavior caused by the increases in volatility during times of crisis.

The empirical insights from our analysis can be summarized as follows. First, there is at least one cointegrating relationship between oil and stock markets under the consideration of the CAC40 index and the LDJI, meaning that oil and stock markets converge to a common equilibrium in the long run. Second, the linkages between oil and 
stock markets vary over time and they can be either negative or positive depending on the time periods such as bullish and bearish markets and the underlying economic shocks which are resulted from demand side or supply sides. Finally as in previous studies, oil price shocks in periods of world turmoil and political events are found to exert important effects on the relationship between oil and stock market prices. All in all, our findings, which are supportive of important stylized facts of oil and stock market returns such as long-run cointegration, volatility asymmetry, asymmetric correlation, and long memory, suggest that assessing the time-varying comovement between oil and stock markets with the c-DCC-FIGARCH would be misleading if their long-run cointegration is not accounted for. Given the country-specific dynamic links between oil and stock markets (negative vs. positive), investors can thus refer to the price fluctuations in the oil markets in order to optimally design their diversification and hedging strategies, considering long-range volatility dependence in oil and stock market, price persistence patterns, and fluctuation of oil price. Also, policymakers may make appropriate policies to reduce the impact of adverse oil price effects on production and economic activities. A possible way to construct time-varying optimal hedging strategy based on the results of our c-DCCFIAPARCH can be found in Arouri et al. (2011).

The impact of the oil price decrease on the development of the global economy depends on the causes of the oil price fall. Hervé et al. (2010), Peersman and Van Robays, (2011) and Cashin et al. (2014) show that a price fall due to reduced oil demand haven't the same positive effects on the global economy as a price fall due to an increased oil supply. For example, the low price of oil is caused by reduced demand of oil because of the slower economic growth in Chinese economy. This demand-driven price fall is symptomatic of worsened growth prospects. The extent of the effects also depends on how countries adjust their fiscal and monetary policies in response to the fall in prices.

Received 31 August 2014, Revised 1 October 2015, Accepted 7 January 2016 


\section{References}

Aielli, G.P. "Consistent estimation of large scale dynamic conditional correlations." University of Messina, Department of Economics, Statistics, Mathematics and Sociolog Working paper, no. 47 (2008).

Aloui, R., Ben Aïssa, M.S., Nguyen, D.K. "Conditional dependence structure between oil prices and exchange rates: A copula-GARCH approach." Journal of International Money and Finance 32 (2013): 719-738.

Arouri, M.., Nguyen, D.K “Oil prices, stock markets and portfolio investment: evidence from sector analysis in Europe over the last decade." Energy Policy, no. 38 (2010): $4528-4539$.

Arouri, M., Jouini, J., Nguyen, D.K. "Volatility spillovers between oil prices and stock sector returns: implications for portfolio management," Journal of International Money and Finance, no. 30 (2011): 1387-1405.

Arouri, M., Rault, C. "Oil prices and stock markets in GCC countries: Empirical evidence from panel analysis." International Journal of Finance and Economics, no 17 (2011): 242-253.

Bollerslev, T. "Modelling the coherence in short-run nominal exchange rates: A multivariate generalized arch model." Review of Economics and Statistics 72, no. 3 (1990): 498-505.

Cashin, P., K. Mohaddes, and M. Raissi "The Global Impact of the Systemic Economies and MENA Business Cycles." International Monetary Fund Working Paper 12/255, 2012.

Chiou, J.S., Lee, Y.H. "Jump dynamics and volatility: Oil and the stock markets." Energy 34 (2009): 788-796.

Choi, K., Hammoudeh, S. "Behavior of GCC stock markets and impacts of US oil and financial markets." Research in International Business and Finance 20 (1) (2006): 2244.

Cifarelli, G., Paladino, G. "Oil price dynamics and speculation: A multivariate financial approach." Energy Economics 32 (2010): 363 - 372. 
Cologni, A., Manera, M. "Oil prices, inflation and interest rates in a structural cointegrated VAR model for the G-7 countries." Energy Economics 38 (2008): 856-888.

Cunado, J., Perez de Garcia, F. "Oil prices, economic activity and inflation: evidence for some Asian countries."Quarterly Review of Economics and Finance 45 (1) (2005): 6583.

Davidson, J. "A model of fractional cointegration and tests for cointegration using the bootstrap.” Journal of Econometrics 110 (2002): 187-212.

Davidson, J. "Testing for Fractional Cointegration: the Relationship between Government Popularity and Economic Performance in the UK." in New Trends in Macroeconomics, C. Diebolt and C. Kyrtsou (Springer-Verlag, 2005).

Davidson, J., David, B., David, P. "Support for governments and leaders: Fractional cointegration analysis of poll evidence from the UK, 1960-2004." Studies in Nonlinear Dynamic and Econometrics 10 (2006): 1-21.

Ding, Z., Granger, C.W.J., Engle, R.F. “A long memory property of stock market returns and a new model." Journal of Empirical Finance 1 (1993): 83-106.

Engel, R.F., Granger, C.W.J. "Cointegration and error correction: Representation, estimation and testing." Econometrica 55 (1987): 250-276.

Engel, R.F. "Dynamic conditional correlation: A simple class of multivariate generalized autoregressive conditional heteroskedasticity models." Journal of Business \& Economic Statistics 20 (2002): 339-350.

Filis, G., Degiannakis, S., Floros, C. "Dynamic correlation between stock market and oil prices: The case of oil-importing and oil-exporting countries." International Review of Financial Analysis 20 (2011): 152-164.

Gao, L., Süss, S. "Market Sentiment in Commodity Futures Returns." Journal of Empirical Finance 33 (2015): 84-103.

Granger, C.W.J. "Investigating casual relations by econometric models and crossspectral methods." Econometrica 37 (1969): 424-438.

Granger, C.W.J. "Developments in the study of cointegrated economic variables." Oxford Bulletin of Economics and Statistics 48 (1986) 213-228.

Granger, C.W.J. "Some recent developments in a concept of causality." Journal of 
Econometrics 39 (1988) 199-211.

Hervé K., I. Koske, N. Pain and F. Sédillot. "The macroeconomic policy challenges of continued globalization." OECD Economic Studies 44 (2008).

Hamilton, J.D. "Oil and the macroeconomy since World War II." Journal of Political Economy 91 (1983): 228-248.

Hamilton, J.D. “Understanding crude oil prices.” Energy Journal, 30(2) (2009): 179206.

Huang, R.D., Masulis, R.W., Stoll, H.R. "Energy shocks and financial markets.” Journal of Futures Markets 16 (1996): 1-27.

Jones, C., Kaul, G. “Oil and stock markets.” Journal of Finance, 51 (1996): 463-491.

Li, W.K., McLeod, A.I. "Distribution of the residual autocorrelation in multivariate ARMA time series models." Journal of the Royal Statistical Society 43 (1981): 231-239.

Malik, F., Ewing, B.T. "Volatility transmission between oil prices and equity sector returns." International Review of Financial Analysis 18 (2009): 95-100.

Nielsen, M., Shimotsu, K. "Determining the cointegrating rank in nonstationary fractional systems by the exact local whittle approach." Journal of Econometrics 141 (2007): 574-596.

Peersman, G. and I. Van Robays "Cross-country di§erences in the e§ects of oil shocks." Energy Economics 34 (5) (2012): 1532-1547.

Robinson, P.M., Yajima, Y. "Determination of cointegration rank in fractional systems." Journal of Econometrics, 106 (2002) 217-241.

Sadorsky, P. "Oil price shocks and stock market activity.” Energy Economics 21 (1999): 449-469.

Shimotsu, K. "Exact local whittle estimation of fractional integration with unknown mean and time trend." Econometric Theory 26 (2010): 501-540.

Shimotsu, K., Phillips, P.C.B. "Exact local whittle estimation of fractional integration." Annals of Statistics 33 (2005): 1890-1933.

Tse, Y.K. "The conditional heteroscedasticity of the yen-dollar exchange rate." Journal of Applied Econometrics 13 (1998): 49-55. 